\title{
Epitaxy of SrTiO3 on silicon: the knitting machine strategy
}

\author{
Guillaume Saint-Girons ${ }^{1^{*}}$, Romain Bachelet ${ }^{1}, R^{2}$ ahma Moalla', Benjamin Meunier ${ }^{1}$, Lamis Loua- \\ hadj $^{2}$, Bruno Canut ${ }^{3}$, Adrian Carretero-Genevrier ${ }^{1}$, Jaume Gazquez ${ }^{4}$, Philippe Regreny ${ }^{1}$, Claude \\ Botella', José Penuelas ${ }^{1}$, Mathieu G. Silly ${ }^{5}$, Fausto Sirotti ${ }^{5}$ and Geneviève Grenet ${ }^{1}$
}

${ }^{1}$ Université de Lyon, Institut des Nanotechnologies de Lyon (UMR5270/CNRS), Ecole Centrale de Lyon, 36 avenue

Guy de Collongue, F-69134 Ecully cedex, France

${ }^{2}$ RIBER SA, 31 rue Casimir Périer, F-95870 Bezons, France

${ }^{3}$ Université de Lyon, Institut des Nanotechnologies de Lyon (UMR5270/CNRS), INSA, Bât. Blaise Pascal, 7 avenue

Jean Capelle, F-69621 Villeurbanne cedex, France

${ }^{4}$ Institut de Ciència de Materials de Barcelona (ICMAB-CSIC), Campus UAB, E-o8193 Bellaterra, Catalunya, Spain

${ }^{5}$ Société Civile Synchrotron SOLEIL (ligne TEMPO), L'Orme des Merisiers, Saint-Aubin BP 48, F-91192 Gif-sur

Yvette cedex, France

\begin{abstract}
SrTiO}_{3}$ (STO) crystalline layers grown on $\mathrm{Si}$ open unique perspectives for the monolithic integration of func-tional oxides in silicon based devices, but their fabrication by molecular beam epitaxy (MBE) is challenging due to un-wanted interface reactions. Here we show that the formation of single-crystal STO layers on Si by MBE at the moderate growth temperature imposed by these interface reactions results from the crystallization of a partiallyseparated amor-phous mixture of $\mathrm{SrO}$ and $\mathrm{TiO}_{2}$ activated by an excess of $\mathrm{Sr}$. We identify the atomic pathway of this mechanism and show that it leads to an antiphase domain morphology. Based on these results, we suggest and test alternative STO growth strategies to avoid antiphase boundary formation and improve significantly the STO structural quality. The understand-ing provided by these results offers promising prospects to crystallize perovskite oxides on semiconductors at moderate temperature and circumvent the issue of parasitic interface reactions.
\end{abstract}

\section{Introduction}

Functional oxides of the perovskite family present a variety of physical properties (ferroelectricity, ferromagnetism, superconductivity, high Pockels coefficients, ...) that make them very attractive for applications in the micro-optoelectronic field. ${ }^{1}$ These materials are classically used as thin layers grown on oxide substrates, mainly $\mathrm{SrTiO}_{3}$ (STO). Important perspectives for the integration of new functionalities on silicon and other semiconductor platforms, and therefore for the fabrication of innovative devices combining the physical properties of functional oxides and semiconductors, are offered by the advances in epitaxy of $\mathrm{ABO}_{3}$ perovskites on semiconductors using molecular beam epitaxy (MBE). From the material science point of view, STO/Si can be considered as a prototypical system to understand the impact of structural and chemical heterogeneity on crystal growth.

Controlling the chemical reactions between the growing layer and the substrate is one of the main challenges related to the epitaxial growth of perovskite oxides on semiconductor and particularly STO on $\mathrm{Si}$, as the interface between these materials has been predicted as thermodynamically instable. ${ }^{2}$ This is to a certain extent made possible by using a Sr-based treatment of the Si surface, as evidenced since the very first studies of this system ${ }^{3,4}$, and popularized by McKee et al. ${ }^{5}$ Such procedure or its derivatives $^{6,7}$ are widely used to grow STO/Si. However, even on a Sr-treated Si surface, interface reactions significantly restrain the actual window in which STO can be grown. ${ }^{6,8,9,10,11}$ Deposition must be initiated at low temperature (between room temperature and $400^{\circ} \mathrm{C}$ ) and under low $\mathrm{O}_{2}$ partial pressure (below $10^{-7}$ Torr, typically in the few $10^{-8}$ Torr range). Under these conditions, an amorphous or partly amorphous STO layer is formed, and an annealing under ultra-high vacuum (UHV) ${ }^{12}$ or low $\mathrm{O}_{2}$ partial pressure ${ }^{8}$ is required to obtain crystalline STO. Further STO growth can then be conducted at higher temperature $\left(400-550^{\circ} \mathrm{C}\right)$ under higher $\mathrm{O}_{2}$ partial pressure (ranging from few $10^{-8}$ to $10^{-6}$ Torr). This process leads to satisfying STO structural properties ${ }^{13,14,15,16,17}$, but the quality of STO/Si layers is still far lower than that observed for STO layers grown on STO substrates, for which atomic layer-by-layer or step-flow growth can be achieved thanks to higher temperature process, or for more mature materials such as III-V or SiGe semiconductors. Obviously, the structural quality of STO layers grown on $\mathrm{Si}$ is limited by the required recrystallization step (designated as topotactic reaction ${ }^{18}$ or as solid phase epitaxy ${ }^{10}$ by some authors) which has only barely been studied.

In this context, we show that the quasi-amorphous material deposited at low temperature at the initial stages of the growth of STO on $\mathrm{Si}$ is predominantly composed of a 
partially separated mixture of $\mathrm{TiO}_{2}$ and SrO. STO crystallites nucleate at the interface with $\mathrm{Si}$ (from which they inherit their crystallographic orientation) and extend at the expense of the amorphous matrix by lateral propagation of a Sr-rich crystallization front. This excess of $\mathrm{Sr}$ allows $\mathrm{TiO}_{2}$ incorporation in the STO lattice at the moderated temperature used to avoid parasitic interface reactions by a mechanism comparable to the $\mathrm{SrO} / \mathrm{TiO}_{2}$ layer swap mechanism described in Ref.19. An antiphase domain structure, where phase domains are separated by vertical $\mathrm{SrO}$ stacking faults, results from this crystallization process. Based on this understanding, we show how convenient engineering of the early stages of STO growth on Si enhances STO crystallization. This process, that can be adapted for the growth of other perovskite oxides on other semiconductors, offers promising prospects to enhance the structural properties of oxide thin layers grown on semiconductors.

\section{Experimental section}

A two-steps method, extensively described in the supporting information, was used for STO growth by MBE: deposition of a partially amorphous 10 ML thick STO layer at low temperature $\left(360^{\circ} \mathrm{C}\right)$ to prevent interface reactions, annealing under $\mathrm{UHV}$ at $420^{\circ} \mathrm{C}$ leading to STO crystallization followed by further STO growth at this temperature until $11 \mathrm{~nm}$ was reached. $\mathrm{Sr}$ and $\mathrm{Ti}$ fluxes were carefully calibrated using reflection high-energy electron diffraction (RHEED), quartz crystal microbalance (QCM) and Rutherford backscattering (RBS). The calibration procedure and determination of the experimental uncertainty on cationic composition are detailed in the supporting information. Eight samples were grown with different cationic compositions, namely samples A, B, C, D, E, F, H and G with Sr/Ti ratios of o.677, 0.902, 1, 1.004, $1.015,1.021,1.063$ and 1.127, respectively (see Tab.SF1 in the supporting information). After growth, all the samples (except sample $\mathrm{H}$, grown in a second phase for transmission electron microscopy analyses) were studied by X-ray photoelectron spectroscopy, at SOLEIL synchrotron (TEMPO beamline) using an incident beam energy of $1400 \mathrm{eV}$, or using an in-house XPS set-up equipped with a standard Al-K $\alpha$ monochromatic source at $1486.7 \mathrm{eV}$. The samples were also analyzed by X-Ray diffraction (XRD), using a Rigaku Smartlab diffractometer equipped with a high brilliance rotating anode and an in-plane arm allowing direct measurement of the in-plane lattice parameter. Samples C, D, E and $\mathrm{H}$ were analyzed using high-angle annular dark field scanning transmission electron microscopy (HAADF-STEM). In the HAADF imaging mode the intensity of an atomic column roughly scales with the square of the atomic number $(\mathrm{Z})$. In this situation, the brightest spots in a Z-contrast image represent the heaviest atomic columns, $\mathrm{Sr}$, followed by $\mathrm{Ti}$ and finally by $\mathrm{Si}$, which gives the weakest contrast. All the STEM images shown in this work have been acquired with a NION UltraSTEM, equipped with a $5^{\text {th }}$ order NION aberration corrector and operated at $100 \mathrm{kV}$. All cross sectional spec- imens for STEM were prepared by conventional methods, by grinding, dimpling, and $\mathrm{Ar}$ ion milling.

\section{STO crystallization by ordering of a partially sepa- rated mixture}

The STEM images of samples $\mathrm{C}(\mathrm{Sr} / \mathrm{Ti}=1), \mathrm{D}(\mathrm{Sr} / \mathrm{Ti}=$ 1.004) $\mathrm{E}(\mathrm{Sr} / \mathrm{Ti}=1.015)$ and $\mathrm{H}(\mathrm{Sr} / \mathrm{Ti}=1.063)$ are displayed in Fig. 1.

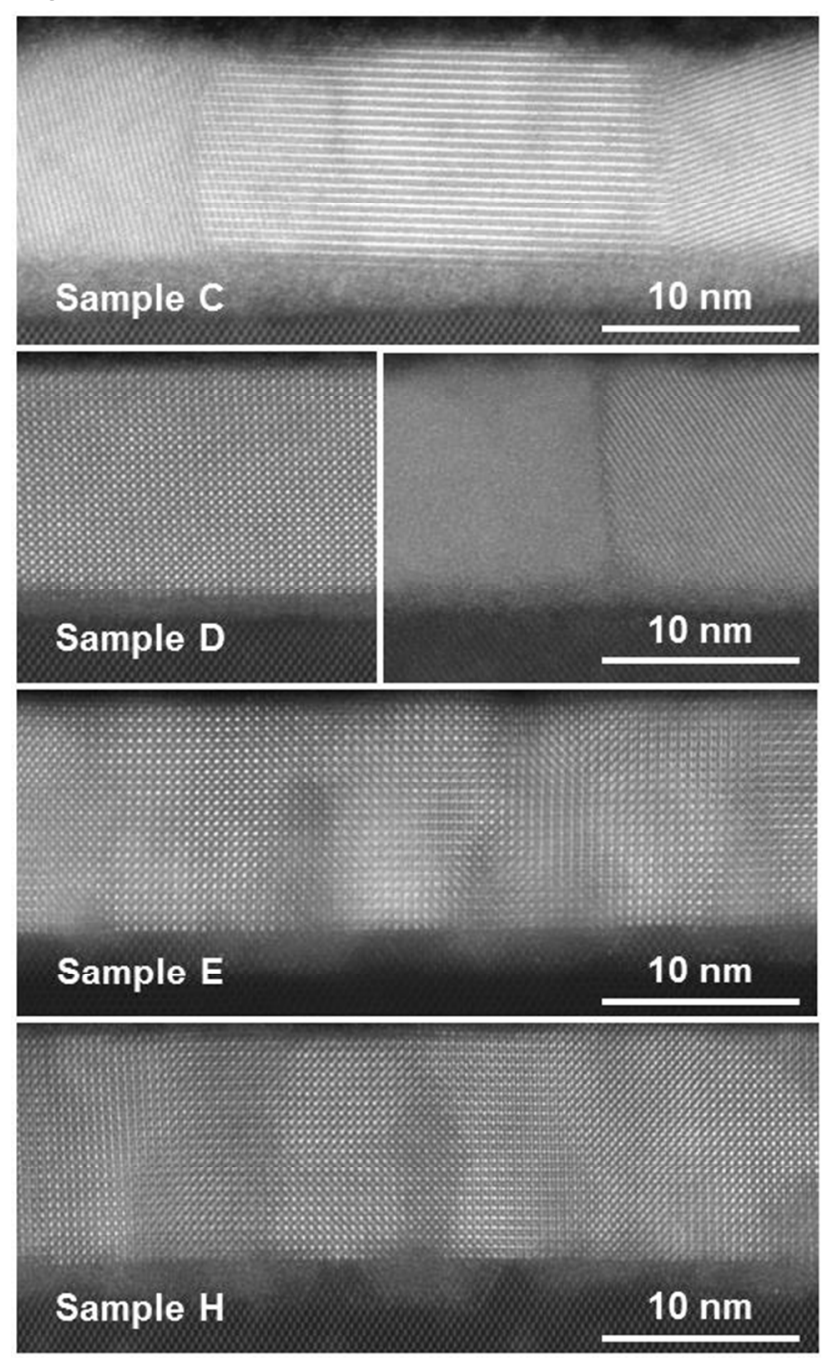

Figure 1 : STEM images of samples C, D E and H. The defects in samples $\mathrm{E}$ and $\mathrm{H}$ are $\mathrm{SrO}$ stacking faults, as shown in the supporting information.

These images show that for $\mathrm{Sr} / \mathrm{Ti}=1$ (sample C), STO presents a very disturbed morphology with the presence of polycrystalline and amorphous zones. Such amorphous zones are still detected in sample $\mathrm{D}(\mathrm{Sr} / \mathrm{Ti}=1.004)$, and single crystal STO is obtained only for $\mathrm{Sr} / \mathrm{Ti}$ ratios larger than 1.015 (sample E and H). Extended defects are clearly detected in these samples. These defects are $\mathrm{SrO}$ stacking faults (extra $\mathrm{SrO}$ planes in the STO lattice) lying either perpendicular to the substrate surface ((o10) stacking faults) or parallel to the substrate surface ((ool) stacking faults), as shown in the supporting information (Fig. SF7 and SF8). It is noteworthy that these defects are mostly 
vertical ((o10) stacking faults) at $\mathrm{Sr} / \mathrm{Ti}=1.015$ (sample E), as discussed in further details in the next section.

The chemistry of the samples and its dependency on $\mathrm{Sr} / \mathrm{Ti}$ ratio was examined based on XPS measurements carried out at the TEMPO beamline of the SOLEIL synchrotron and using an in-house spectrometer. The Srzd and $\mathrm{Ti}_{2} \mathrm{P}_{3 / 2}$ core levels recorded on the samples were decomposed into components, as shown in Fig. 2a for sample A (for the other samples, see the supporting information, Fig. $\mathrm{SF}_{2}$ ). The $\mathrm{Ti}_{2} \mathrm{p}_{1 / 2}$ core level has also been measured and analyzed for all samples. It shows, as expected, same behavior as the $\operatorname{Ti}_{2} \mathrm{P}_{3 / 2}$ core level and is thus not displayed here, for the sake of clarity. Evolution of the Ors core level is given in the supporting information (Fig. $\mathrm{SF}_{2}$ ).

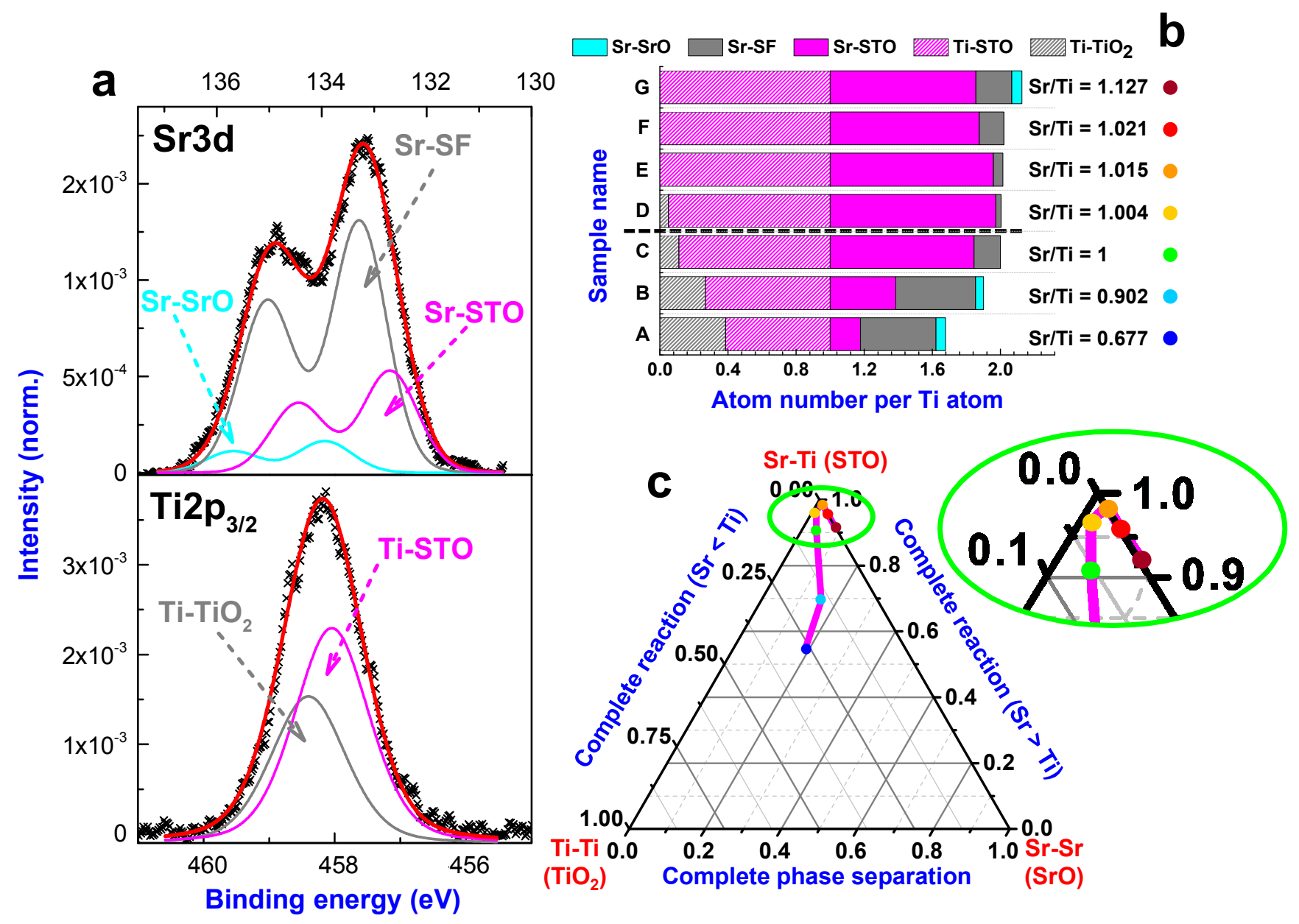

Figure 2: Composition of the samples as a function of the $\mathrm{Sr} / \mathrm{Ti}$ ratio. a $\mathrm{Ti}_{2} \mathrm{p}_{3 / 2}$ and $\mathrm{Sr} 3 \mathrm{~d}$ core levels of sample $\mathrm{A}(\mathrm{Sr} / \mathrm{Ti}=$ o.677) and associated deconvolutions. b Atomic composition of samples (in atom number per Ti atom) as extracted from XPS. The mixture composition is the closest to that of perfect $\mathrm{STO}$ for $\mathrm{Sr} / \mathrm{Ti}>1$, whereas at $\mathrm{Sr} / \mathrm{Ti}=1$ it contains a significant amount of $\mathrm{Ti}_{-}-\mathrm{TiO}_{2}$ and $\mathrm{Sr}-\mathrm{SF}$ atoms. c Chemical order of the samples depending on the $\mathrm{Sr} / \mathrm{Ti}$ ratio, quantified by counting the $\mathrm{Sr}-\mathrm{Sr}$, Ti-Ti and $\mathrm{Sr}$-Ti pairs in the samples based on XPS measurements. In this ternary diagram, each apex corresponds to a pure compound (SrO: $\mathrm{Sr}-\mathrm{Sr}$ pairs only, $\mathrm{TiO}_{2}$ : $\mathrm{Ti}$-Ti pairs only and $\mathrm{STO}$ : $\mathrm{Sr}-\mathrm{Ti}$ pairs only). The point corresponding to a given mixture containing $\mathrm{x}$ $\mathrm{Sr}-\mathrm{Sr}$ pairs, y Ti-Ti pairs and z Sr-Ti pairs is the barycenter of the three apexes weighted by $\mathrm{x}$, y and $\mathrm{z}$. A point representing a mixture free of one of the three pair types lies on the side opposite to the apex corresponding to this pair type. Color code for data points indicate sample compositions (see b). 
The pink components in Srzd and Ti2p core levels, labelled Sr-STO and Ti-STO in the following, correspond to $\mathrm{Sr}$ and $\mathrm{Ti}$ atoms in a STO environment. In particular, the binding-energy distance between $\mathrm{Sr}-\mathrm{STO}$ and Ti-STO $(325.35 \mathrm{eV})$ corresponds to that reported for STO. ${ }^{20}$ The grey component in the Ti2 $\mathrm{p}_{3 / 2}$ core level is shifted by 0.36 $\mathrm{eV}$ toward low binding energies with respect to the $\mathrm{Ti}-$ STO component. This value is close to that reported in Ref. 20 for the chemical shift between Ti in a STO environment and $\mathrm{Ti}$ in $\mathrm{a} \mathrm{TiO}_{2}$ environment $(0.40 \pm 0.04 \mathrm{eV})$. This shift is due to the charge transfer between $\mathrm{Sr}$ atoms and the $\mathrm{O}$ atoms to which the Ti atoms of the STO lattice are bonded, making these $\mathrm{O}$ atoms "less oxidant" in STO than they are in $\mathrm{TiO}_{2}$. The grey component is thus attributed to $\mathrm{Ti}$ atoms in a $\mathrm{TiO}_{2}$ environment, and labelled $\mathrm{Ti}^{-} \mathrm{TiO}_{2}$ in the following. Similarly, the chemical shift between the blue and pink components in the Srzd core levels of samples $\mathrm{A}, \mathrm{B}$ and $\mathrm{E}$ is $1.24 \mathrm{eV}$, in the same range as that reported for the chemical shift between $\mathrm{Sr}$ in a $\mathrm{SrO}$ environment and $\mathrm{Sr}$ in a STO environment (in the $1-1.2 \mathrm{eV}$ range $^{21,22,23}$ ). This component, labelled $\mathrm{Sr}-\mathrm{SrO}$ in the following, is thus attributed to $\mathrm{Sr}$ atoms in a $\mathrm{SrO}$ environment. The grey component in the Srzd core level, shifted by $0.6 \mathrm{eV}$ with respect to the Sr-STO component, corresponds to $\mathrm{Sr}$ atoms in $\mathrm{SrO}$ stacking fault environment, as shown in the supporting information (Fig. $\mathrm{SF}_{4}$ and associated discussion). This component is labelled Sr-SF in the following. It has to be noted here that XPS is a method purely sensitive to sample chemistry and not to crystalline order. As a consequence, detecting Sr-STO and SrSF signatures in the samples does not imply the presence neither of crystalline STO, nor of SrO stacking fauts in the crystalline meaning of the term (additional $\mathrm{SrO}$ planes in an organized STO lattice). It simply implies that atoms have locally the same chemical environment as that they have in a STO crystal or around a SrO stacking fault in a STO crystal. Crystallinity is assessed in this study by STEM images (Fig. 1), RHEED patterns (Fig. 3) and XRD experiments (next section).

The thin films are thus composed of a mixture of $\mathrm{SrO}$, $\mathrm{TiO}_{2}$, STO, and of $\mathrm{Sr}$ atoms in a $\mathrm{SrO}$ stacking fault environment, the proportions of which depend on the $\mathrm{Sr} / \mathrm{Ti}$ ratio. The evolution of the sample composition as a function of the $\mathrm{Sr} / \mathrm{Ti}$ ratio is plotted in Fig. 2b. Surprisingly, at $\mathrm{Sr} / \mathrm{Ti}=1$, the mixture contains a significant proportion of atoms in non-STO environments ( $15 \%$ of $\mathrm{Sr}$ atoms in $\mathrm{Sr}-$ SF environment, $12 \%$ of $\mathrm{Ti}$ atoms in $\mathrm{Ti}-\mathrm{TiO}_{2}$ environment) and a slight excess of $\mathrm{Sr}$ is required to approach the organization expected for perfect STO ("optimal" point at $\mathrm{Sr} / \mathrm{Ti}=1.004$ for $\mathrm{Sr}$ atoms, and $\mathrm{Sr} / \mathrm{Ti}=1.015$ for $\mathrm{Ti}$ atoms). Below the optimal $\mathrm{Sr} / \mathrm{Ti}$ ratio, a large proportion of $\mathrm{Ti}$ atoms have a $\mathrm{TiO}_{2}$ chemical environment, as a priori expected in the $\mathrm{Sr} / \mathrm{Ti}<1$ region. Less intuitive is the observation of a significant proportion of $\mathrm{Ti}$ atoms in $\mathrm{TiO}_{2}$ environment in the $\mathrm{Sr} / \mathrm{Ti}>1$ region ( $\mathrm{Sr}$ rich region), up to $\mathrm{Sr} / \mathrm{Ti}=1.015$, and of a very large amount of $\mathrm{Sr}$ atoms in $\mathrm{Sr}-$ $\mathrm{SrO}$ and $\mathrm{Sr}-\mathrm{SF}$ environments in the $\mathrm{Ti}$ rich region. This shows first that despite $\mathrm{Sr}$ deficiency, the chemical reac- tion between $\mathrm{SrO}$ and $\mathrm{TiO}_{2}$ to form STO is not complete in the Ti-rich region, and second that an excess of $\mathrm{Sr}$ corresponding to a $\mathrm{Sr} / \mathrm{Ti}$ ratio of 1.015 is required to make this reaction complete. Partial phase separation (STO $\rightarrow$ SrO stacking faults $+\mathrm{TiO}_{2}$ ) is observed in the Ti-rich region and in the $\mathrm{Sr}$-rich region, up to $\mathrm{Sr} / \mathrm{Ti}=1.015$. Above this composition, all $\mathrm{Ti}$ atoms are in STO environment, while a significant proportion of $\mathrm{Sr}$ atoms are in $\mathrm{Sr}-\mathrm{SF}$ environment, showing that the excess of $\mathrm{Sr}$ is absorbed in the lattice by forming $\mathrm{SrO}$ stacking faults.

The chemical organization of the mixture can be more comprehensively assessed by deriving the proportions of $\mathrm{Sr}-\mathrm{Sr}, \mathrm{Ti}-\mathrm{Ti}$ and $\mathrm{Sr}-\mathrm{Ti}$ pairs from XPS results, as the areas of the XPS components are proportional to the number of atoms in a given chemical environment (see supporting information, Fig. $\mathrm{SF}_{5}$ ). These proportions are plotted for samples A-G in the ternary diagram of Fig. 2c. In such a diagram, the point representing a mixture free of one of the three elements lies on the side opposite to the apex corresponding to this element, so that the $\mathrm{Ti}-\mathrm{Ti} / \mathrm{Sr}-\mathrm{Ti}$ segment corresponds to complete reaction in the $\mathrm{Sr}<\mathrm{Ti}$ region (neither $\mathrm{SrO}$ nor $\mathrm{SrO}$ stacking faults in the mixture), the $\mathrm{Sr}-\mathrm{Sr} / \mathrm{Sr}-\mathrm{Ti}$ segment corresponds to complete reaction in the $\mathrm{Sr}>\mathrm{Ti}$ region (no $\mathrm{TiO}_{2}$ in the mixture), and the $\mathrm{Ti}-\mathrm{Ti} / \mathrm{Sr}-\mathrm{Sr}$ segment corresponds to complete phase separation (no STO in the mixture). Fig. $2 \mathrm{c}$ confirms that the reaction between $\mathrm{SrO}$ and $\mathrm{TiO}_{2}$ to form STO is incomplete in the Ti-rich region (no data points on the $\mathrm{Ti}-\mathrm{Ti} / \mathrm{Sr}$-Ti segment), remains incomplete in the $\mathrm{Sr}$ rich region up to $\mathrm{Sr} / \mathrm{Ti}=1.015$ and is complete for $\mathrm{Sr} / \mathrm{Ti} \geq$ 1.015. To summarize at this point, an excess of $\mathrm{Sr}$ is required to obtain complete reaction between $\mathrm{SrO}$ and $\mathrm{TiO}_{2}$ to form STO: Sr acts as a catalyst for STO formation. The optimal $\mathrm{Sr}$ excess corresponds in our growth conditions to a $\mathrm{Sr} / \mathrm{Ti}$ ratio of 1.015. A consequence of this is that pure STO cannot be obtained in standard MBE growth conditions: the excess of $\mathrm{Sr}$ required for optimal alloy ordering is absorbed in the lattice under the form of $\mathrm{SrO}$ stacking faults.

Crystallinity and completeness of the chemical reaction between $\mathrm{SrO}$ and $\mathrm{TiO}_{2}$ to form STO are correlated, as shown in Fig. 3. On this graph, the chemistry of the mixture is described using a normalized short-order parameter $(\mathrm{P})$, defined as

$$
P=\frac{n(S r-T i)-(n(S r-S r)+n(T i-T i))}{n(S r-T i)+n(S r-S r)+n(T i-T i)}
$$

where $n(\mathrm{Sr}-\mathrm{Ti}), \mathrm{n}(\mathrm{Sr}-\mathrm{Sr})$ and $\mathrm{n}(\mathrm{Ti}-\mathrm{Ti})$ designate the concentrations of $\mathrm{Sr}-\mathrm{Ti}, \mathrm{Sr}-\mathrm{Sr}$ and $\mathrm{Ti}-\mathrm{Ti}$ bonds in the samples, and are extracted from XPS results. $\mathrm{P}=1$ in a perfect STO crystal, and -1 in a fully separated mixture of $\mathrm{SrO}$ and $\mathrm{TiO}_{2} . \mathrm{P}$ is compared to the evolution of the amplitude of the STO (oo2) XRD peak, extracted from XRD radial scans (Fig. SF6) and normalized to that of the Si (oo4) peak. 


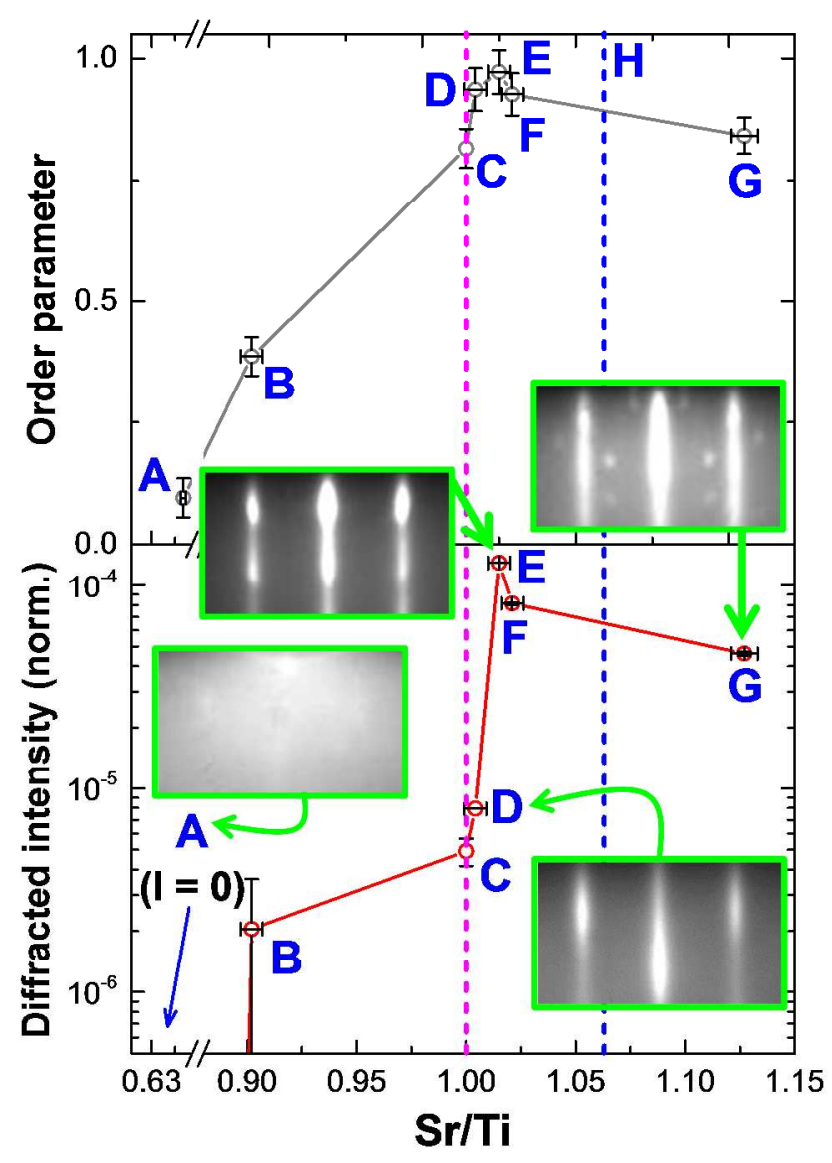

Figure 3: Structural and chemical order as a function of the $\mathbf{S r}$ /Ti ratio. Evolution of the integrated intensity of the $\mathrm{STO}(\mathrm{OO2})$ XRD peak normalized to that of the Si(oo4) peak and of the short-order parameter $\mathrm{P}$ as a function of the $\mathrm{Sr} / \mathrm{Ti}$ ratio. The pink dashed line indicates the stoichiometric composition and the blue dashed line indicate the composition of sample H. Inset: RHEED patterns of some of the samples recorded at the end of STO growth.

$\mathrm{P}$ and the diffracted intensity present comparable evolution as a function of $\mathrm{Sr} / \mathrm{Ti}$, showing a clear correlation between crystalline and chemical order in the samples. In particular, the highest diffracted intensity (corresponding to optimal STO crystallinity) is obtained for $\mathrm{Sr} / \mathrm{Ti}=1.015$, which also corresponds to the maximal value of $\mathrm{P}$ (optimal chemical organization). Above this optimal value, the sample crystallinity is degraded and $\mathrm{P}$ decreases. This is due to the presence of $\mathrm{SrO}$ stacking faults in the samples, also detected by STEM (Fig. 1, Fig. SF7 and SF8). Spots on the RHEED pattern of sample $\mathrm{G}(\mathrm{Sr} / \mathrm{Ti}=1.127)$ indicate the presence of $\mathrm{SrO}$ islands at the sample surface, resulting from $\mathrm{Sr}$ segregation. The chemical signature of these defects is clearly detected by XPS: Fig. $2 \mathrm{~b}$ indicates a clear increase of the proportion of $\mathrm{Sr}$ atoms in Sr-SF environment for $\mathrm{Sr} / \mathrm{Ti}$ values larger than 1.015, and $\mathrm{Sr}$ atoms in $\mathrm{SrO}$ environment are detected in sample $\mathrm{G}$ in correlation with the spotty RHEED pattern. For $\mathrm{Sr} / \mathrm{Ti}<1.015$, the strong reduction of the diffracted intensity with decreasing $\mathrm{Sr} / \mathrm{Ti}$ ratio is also correlated to a reduction of the short-order parameter, i.e. to a degradation of the chemical order. In this region, STEM images (Fig. 1) and RHEED patterns indicate that the thin layers become polycrystalline then amorphous with decreasing $\mathrm{Sr} / \mathrm{Ti}$ ratio. In particular, the RHEED pattern of sample A $(\mathrm{Sr} / \mathrm{Ti}=0.677)$ indicates that the sample is mostly amorphous. This evolution is correlated with the phase separation detected by XPS in this region, suggesting that the amorphous fraction of the thin layers corresponds to zones where the alloy is separated.

The results presented so far show that the formation of the STO crystal on Si in MBE conditions arises from the crystallization and chemical ordering of a partially separated mixture of $\mathrm{TiO}_{2}, \mathrm{SrO}$ and $\mathrm{Sr}$ atoms in a $\mathrm{SrO}$ stacking fault environment, and that this process requires a slight excess of $\mathrm{Sr}$ corresponding to a $\mathrm{Sr} / \mathrm{Ti}$ ratio of 1.015. STO crystallization can thus be viewed as a $\mathrm{Sr}$-assisted chemical reaction between $\mathrm{SrO}$ and $\mathrm{TiO}_{2}$ initially present under an amorphous form. STO crystallization and chemical ordering occur during the UHV annealing step, as shown in the next section where the STO crystallization process is also described in further details.

\section{Crystallization mechanism : the knitting machine}

It is first insightful to analyze in further details the correlation between $\mathrm{SrO}$ stacking fault repartition and $\mathrm{Sr} / \mathrm{Ti}$ ratio. The STEM images of Fig. 1 and those provided in the supporting information (Fig. SF7 and SF8) allow for identifying two types of SrO stacking faults ("horizontal" (oo1) and "vertical" (o10) stacking faults), but the local nature of STEM analysis do not allow for quantitatively assessing their relative abundance in the samples. To do this, we have applied the methodology proposed by Ohnishi et al. $^{24}$ (extensively described in the supporting information, Fig. SF9 and $\mathrm{SF}_{10}$ ) which roughly consists in deriving the concentration of $\mathrm{SrO}$ stacking faults in a STO lattice from the lattice parameter of the crystal, as such defects are known to cause an increase of the lattice constant. ${ }^{25}$ Inand out-of-plane XRD measurements where used to measure STO in- and out-of-plane lattice parameters as a function of the $\mathrm{Sr} / \mathrm{Ti}$ ratio (raw data: Fig. SF6), and the average distance between two successive vertical stacking faults and two successive horizontal stacking faults was extracted from these measurements. The results are displayed in Fig. 4a. 


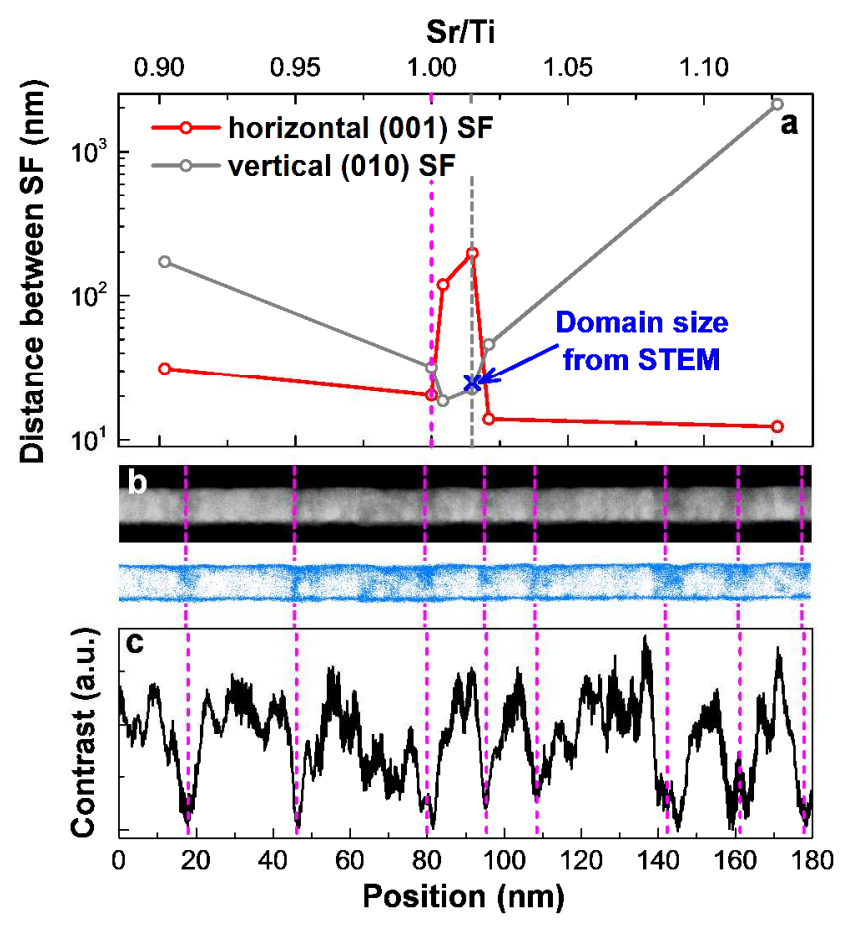

Figure 4: Stacking fault distribution as a function of the $\mathrm{Sr} / \mathrm{Ti}$ ratio. a Red (resp. grey) curve: average distance between two successive horizontal (oo1) (resp. vertical (o10)) stacking faults derived from STO in- and out-of-plane lattice parameters. The pink dashed line indicates the stoichiometric composition, and the grey dashed line indicates $\mathrm{Sr} / \mathrm{Ti}$ $=1.015$. At this composition, the average distance between two successive (o10) stacking faults is $22.7 \mathrm{~nm}$. b Low magnification Z-contrast image of sample $\mathrm{E}(\mathrm{Sr} / \mathrm{Ti}=1.015)$ and associated contour image with enhanced contrast in the faulted regions. c Contrast profile of the Z-contrast image. Pink dashed lines indicate vertical $\mathrm{SrO}$ stacking faults separating antiphase domains. The average antiphase domain size extracted from the STEM image is $24.7 \mathrm{~nm}$.

It is worth noting that this analysis is representative for the crystalline and epitaxial part of the material only, and has thus limited relevance in the low $\mathrm{Sr} / \mathrm{Ti}$ ratio region where the thin layers are mostly amorphous. Despite this, Fig. 4a shows a clear dependency of the stacking fault repartition on the $\mathrm{Sr} / \mathrm{Ti}$ ratio. In particular, this repartition dramatically changes around the "optimal" point corresponding to a Sr/Ti ratio of 1.015, where optimal STO crystallinity and chemical order has been detected. At this point, the average distance between (oo1) stacking faults is maximal and exceeds by far the layer thickness, which basically means that there is no such stacking faults. Oppositely, the average distance between (o10) stacking faults is minimal and rates $22.7 \mathrm{~nm}$, showing that for this specific $\mathrm{Sr} / \mathrm{Ti}$ ratio, $\mathrm{Sr}$ excess is quasi-exclusively incorporated by forming vertical (o10) stacking faults in accordance with the results discussed previously. Fig. 4b displays a low magnification Z-contrast image of the sample grown using a $\mathrm{Sr} / \mathrm{Ti}$ ratio of 1.015, and the associated contour image with enhanced contrast in the $\mathrm{SrO}$ stacking fault regions. This image confirms that all the stacking faults in the sample are vertical (o10) stacking faults. A "columnar-like" microstructure similar to that reported in Ref. 8,26 or 27 is observed, consisting in antiphase domains, shifted from each other by one $\mathrm{d}(110)$ interatomic distance along the [101] direction and separated by (o10) $\mathrm{SrO}$ stacking faults (antiphase boundaries). The average antiphase domain size, extracted from the contrast profile displayed in Fig. 4b, is $24.7 \mathrm{~nm}$ (63.25 STO unit cells). Therefore, the relative excess of $\mathrm{Sr}$ corresponding to this stacking fault density is $(1+63.25) / 63.25$ (one extra $\mathrm{SrO}$ plane every 63.25 STO unit cells), and rates 1.016. It equals, within experimental uncertainty, the $\mathrm{Sr} / \mathrm{Ti}$ ratio used for growing the sample (1.015). It also nearly equals the average distance between two successive (o10) stacking faults derived from XRD measurements $(22.7 \mathrm{~nm})$. This confirms that in conditions where STO crystallinity and chemical ordering are optimal, the excess of $\mathrm{Sr}$ is completely absorbed by the formation of (o10) SrO stacking faults separating defect free antiphase domains. This antiphase domain structure is similar to that reported in Ref. 27. However, in this reference, the authors describe antiphase boundaries made of additional $\mathrm{TiO}_{2}$ planes, resulting either from Si substrate atomic steps or from merging of crystalline domain from different nucleation sites. The results presented here show that excess $\mathrm{Sr}$ can also organize itself into an antiphase boundary microstructure made of additional $\mathrm{SrO}$ planes. We show in the following that this antiphase domain structure results from STO crystallization during UHV annealing. Fig. 5 shows a set of Z-contrast images from three different samples, all grown using a $\mathrm{Sr} / \mathrm{Ti}$ ratio of 1.015, but having the growth stopped at different stages of the UHV annealing step. 
a

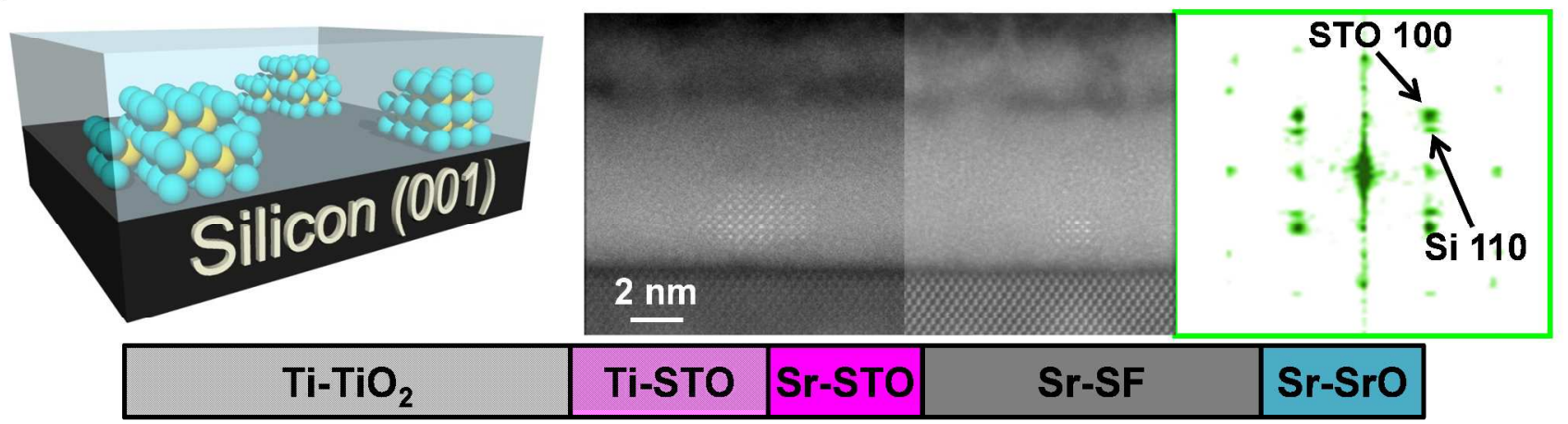

b
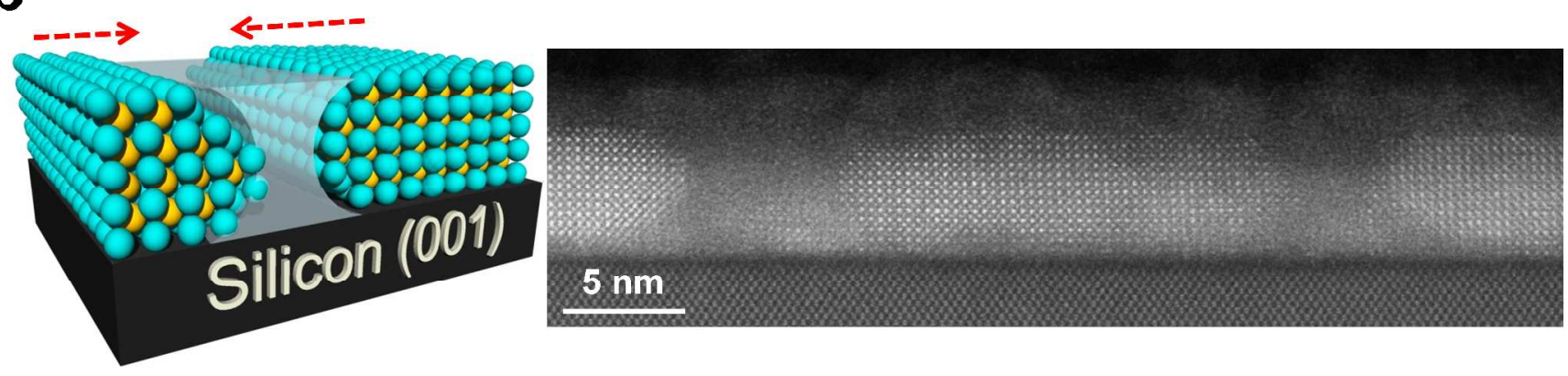

C
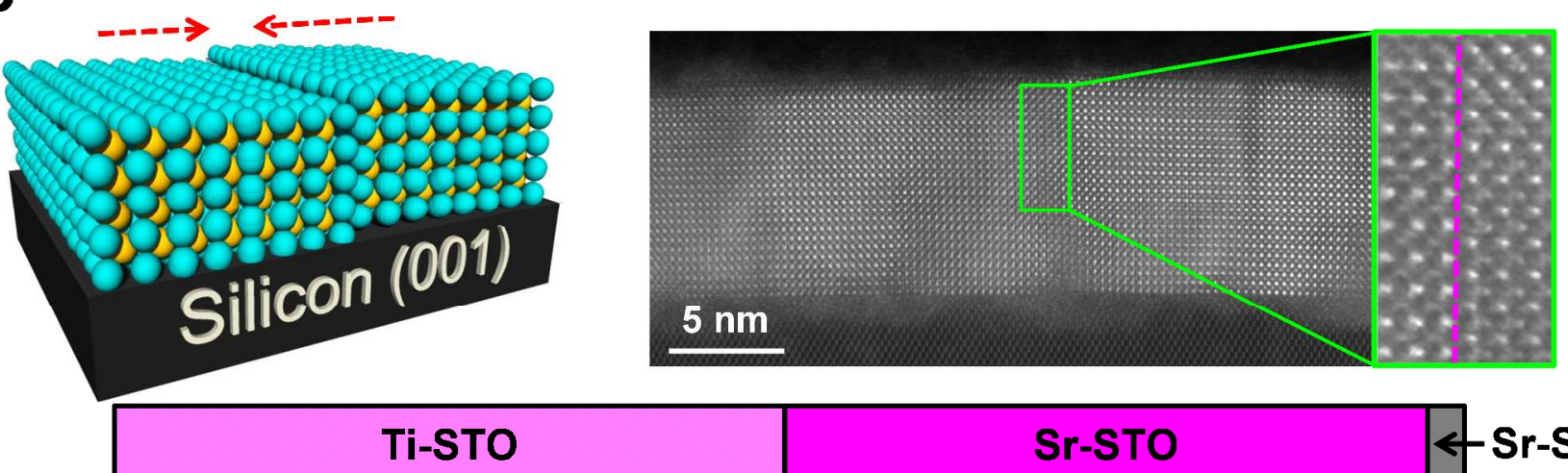

Figure 5: STEM analysis of the STO microstructure evolution during the UHV-annealing step of a sample grown using $\mathbf{S r} / \mathbf{T i}=$ 1.015. a Before annealing. b After $15 \mathrm{~min}$ annealing. c After $30 \mathrm{~min}$ annealing (sample E). Left column: schematic of the crystallization process. Sr atoms are blue, Ti atoms are yellow. Bars indicate the composition of the samples, as deduced from XPS (Fig. SF11).

These images confirm that STO crystallization occurs during the UHV annealing step. Before annealing, the layer consists in an amorphous matrix containing nanometric $(<5 \mathrm{~nm})$ crystallites. These crystallites are located at the $\mathrm{STO} / \mathrm{Si}$ interface, and are in epitaxial relationship with the substrate as shown by the Fourier transform of the Z-contrast image shown in Fig. 5a: STO crystallization is initiated at the Si surface which provides a crystallographically ordered template. At this step, the thin layer is mostly composed of separated $\mathrm{TiO}_{2}, \mathrm{SrO}$, and $\mathrm{Sr}-\mathrm{SF}$ phases, as shown by XPS (Fig. SF11). After 15 min annealing, STO crystal has extended over a significant fraction of the overall volume. Interestingly, crystalline STO do- mains do not contain any $\mathrm{SrO}$ stacking fault, suggesting that the excess of Sr needed for STO crystallization do not incorporate in the crystalline matrix, but remains at the crystallization front. In this regard, it is striking that the growing crystallites in the STEM images are entirely terminated by $\mathrm{SrO}$ planes, and that no $\mathrm{TiO}_{2}$ termination of these crystallites is detected on the entire set of STEM images recorded for this sample. After 30 min annealing, crystallization is completed (crystalline zones have coalesced) and the layer contains a significant concentration of (o10) $\mathrm{SrO}$ stacking faults. The sample is mostly composed of $\mathrm{Sr}$ and $\mathrm{Ti}$ atoms in STO environment, and of a 
small fraction of $\mathrm{Sr}$ atoms in $\mathrm{Sr}-\mathrm{SF}$ environment, as shown by XPS.

This analysis first confirms that STO formation results from the crystallization and chemical ordering of a partially separated mixture, and that this reaction occurs during the UHV annealing step. It also shows that STO crystallization occurs by propagation of a $\mathrm{Sr}$-rich growth front: the required $\mathrm{Sr}$ excess is exactly that needed to form a $\mathrm{SrO}$ termination on all the free surfaces of the growing crystallites. This $\mathrm{SrO}$ termination propagates laterally at the crystallization front during crystallization, as sketched in Fig. 5. When two neighboring crystallites coalesce, their $\mathrm{SrO}$ terminated free surfaces encounter so that there is exactly one extra $\mathrm{SrO}$ plane at each domain boundary, incorporated in the lattice under the form of (o10) $\mathrm{SrO}$ stacking faults.

This Sr-assisted crystallization mechanism is clearly related to the growth conditions (low temperature) imposed by interface reactions between STO and $\mathrm{Si}$, since layer-by-layer homoepitaxial growth of crystalline STO can be achieved by MBE on STO substrate at higher temperature. In this regard, it is interesting to notice that in the "standard" Motorola process ${ }^{28}$, STO growth is initiated at even lower temperature that in the present study (below $200^{\circ} \mathrm{C}$, to be compared to $360^{\circ} \mathrm{C}$ for the sample described here). Despite this difference, it is very likely that the growth mechanism described here is also applicable when Motorola process is used. Indeed, the Motorola process also involves an annealing step under UHV, during which thermal energy is provided to initiate the formation of STO cristallites, their lateral growth at the expense of the surrounding amorphous matrix and their coalescence.

The recent work by Lee et al. ${ }^{19}$ on the stability of the Ruddlesden-Popper homologous series allows for understanding the microscopic origin of the crystallization mechanism described here. Indeed, the authors show in this study that a $\mathrm{TiO}_{2} / \mathrm{SrO} / \mathrm{SrO}$ stack (composed of one $\mathrm{TiO}_{2}$ monolayer deposited on top of two SrO monolayers) grown by MBE on a STO substrate is unstable and spontaneously rearranges itself into a energetically more favorable $\mathrm{SrO} / \mathrm{TiO}_{2} / \mathrm{SrO}$ stack: the top $\mathrm{SrO}$ and $\mathrm{TiO}_{2}$ planes swap. In this work, it is also shown based on density functional theory (DFT) calculations that the atomic pathway of this exchange (sketched in Fig. 6) is related to the attack by a $\mathrm{TiO}_{2}$ molecule of the top $\mathrm{SrO}$ plane to form a tetrahedral complex involving chemical bonds between the $\mathrm{TiO}_{2}$ molecule and the oxygen atoms of the $\mathrm{SrO}$ plane. This mechanism leads to a strong disruption of the $\mathrm{SrO}$ plane and to the formation of a hole, very similar to an oxygen vacancy. The presence of this hole allows the transit of the $\mathrm{TiO}_{2}$ molecules underneath the top $\mathrm{SrO}$ plane and is at the root of the swapping of the $\mathrm{TiO}_{2}$ and $\mathrm{SrO}$ planes. Our observations suggest that similar microscopic mechanism (Fig. 6) is at origin of STO crystallization on $\mathrm{Si}$ : a slight excess of $\mathrm{Sr}$ is required to promote STO crystallization because the crystallites which are growing

at the expense of the surrounding amorphous matrix have to be SrO-terminated.

a

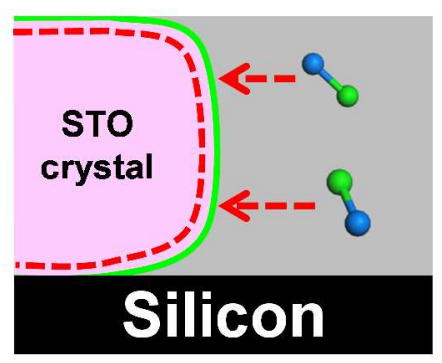

b
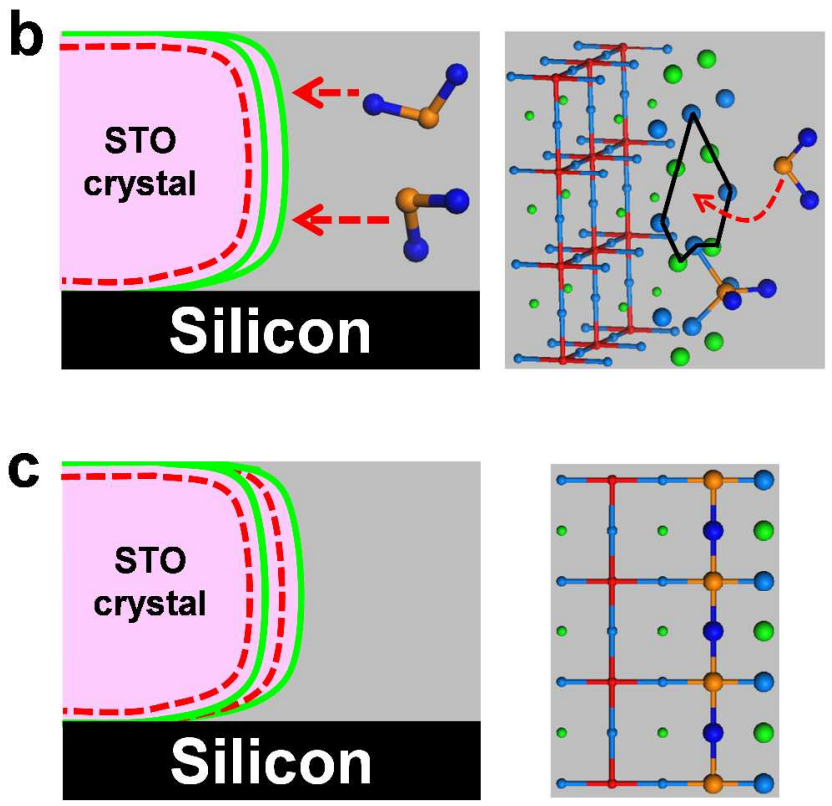

Figure 6: The knitting machine mechanism. a $\mathrm{SrO}$ molecules diffuse from the amorphous phase towards the SrOterminated crystallite and crystallize at its surface to form a $\mathrm{TiO}_{2} / \mathrm{SrO} / \mathrm{SrO}$ termination. b $\mathrm{TiO}_{2}$ molecules diffuse from the amorphous phase towards the $\mathrm{TiO}_{2} / \mathrm{SrO} / \mathrm{SrO}$ terminated surface, and attack the double SrO layer according to the swapping mechanism described in Ref. 19. $\mathrm{TiO}_{2}$ molecules transit underneath the top $\mathrm{SrO}$ layer and are incorporated in the STO crystal, inheriting at this point of its crystalline order. c After this process, the STO crystallite has grown by one monolayer. Following color code is used for the atoms: orange/red: Ti, green: $\mathrm{Sr}$, blue/dark blue: oxygen. Red dashed lines represent $\mathrm{TiO}_{2}$ monolayers, and green lines represent $\mathrm{SrO}$ monolayers.

We named this atomic pathway the "knitting machine" mechanism. In a first step, a SrO layer crystallizes at the growing crystallite surface, leading to the formation of a $\mathrm{TiO}_{2} / \mathrm{SrO} / \mathrm{SrO}$ termination (Fig. 6a). SrO crystallization temperature is very low ( $\mathrm{SrO}$ crystallization has been observed even at room temperature in MBE growth conditions $^{29}$ ) so that crystallization of a $\mathrm{SrO}$ plane at the crystallite surface is a realistic hypothesis, even at the moderated temperature used to avoid interface reactions. Then, as the temperature increases and becomes high enough, the $\mathrm{TiO}_{2}$ aggregates available in the surrounding 
amorphous matrix react with the crystallite surface according to the mechanism described in Ref. 19. They make their way through the top $\mathrm{SrO}$ plane, incorporating at this point into the STO lattice and extending the STO crystal by one unit cell. This sequence is repeated until stopped by coalescence of two neighboring crystallites and formation of the antiphase boundaries.

The proposed mechanism, most probably similar to that which takes place during $\mathrm{Sr}$-mediated quartz crystallization from amorphous silica on $\mathrm{Si}^{30}$ is compatible with our experimental observations. In particular, it implies crystallization by lateral propagation of an excess of $\mathrm{Sr}$ corresponding to a complete $\mathrm{SrO}$ coverage of the growing crystallites, and it also implies that the growing crystallites are always $\mathrm{SrO}$-terminated, as the $\mathrm{TiO}_{2} / \mathrm{SrO} / \mathrm{SrO}$ termination is unstable. In the end, it results in an antiphase domain microstructure with exactly one antiphase boundary ((o10) SrO stacking fault) per initial crystallite. The reason why it takes place during the UHV annealing step is obviously related to the prerequisite of beginning the growth at low temperature to avoid parasitic interface reactions at the interface between oxide and silicon substrate. STO crystallization begins by the formation of $\mathrm{SrO}$ crystallites at moderate temperature. The knitting machine process then starts as soon as enough energy is provided by the annealing to overcome the energy barrier to transform SrO into STO. In this regard, the formation enthalpies of $\mathrm{SrO}$ and of Sr-rich Ruddlesden-Popper phases are much lower than that of $\mathrm{STO}^{31,32}$, which confer on them lower crystallization temperature. This STO crystallization pathway allows for obtaining epitaxial coherency between STO and Si, since STO crystal nucleates in direct contact with the $\mathrm{Si}$ surface, free of any amorphous or polycrystalline parasitic compound.

Engineering the initial growth sequence at the half-monolayer scale to promote STO cristallization

The knitting machine mechanism described here allows STO crystallization on $\mathrm{Si}$ at relatively low temperature. Without this mechanism, epitaxial growth of STO on Si would not be possible due to competition with oxide/Si interface reactions. In this regard, it is striking that many groups having optimized epitaxial growth of STO on Si have converge towards procedures involving an excess of $\mathrm{Sr}$ at the very early stages of the growth. ${ }^{7,11}$ : such $\mathrm{Sr}$-excess is required to promote STO crystallization at intermediate temperature. The drawback is of course that it results in an antiphase domain microstructure, with penalizing effect on the structural and functional properties of the oxide layer. However, the insights on STO/Si growth mechanism provided by the present study open perspectives to develop strategies aimed at avoiding the formation of antiphase boundaries. Such a strategy, sketched in Fig. 7a, has been tried with encouraging preliminary results. a
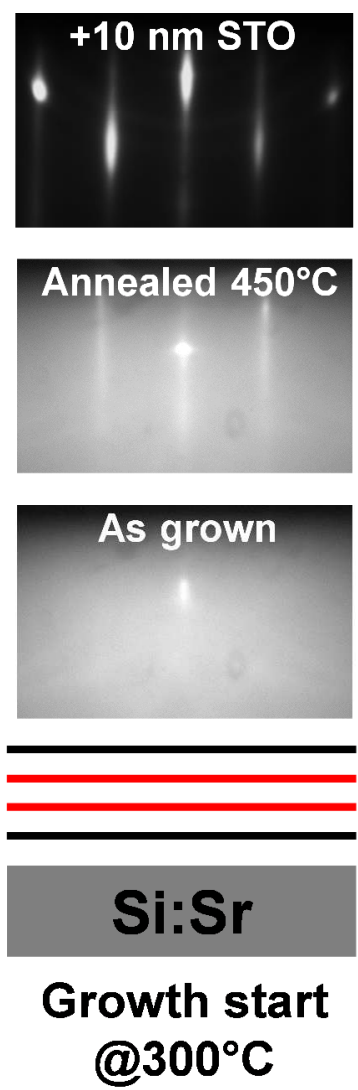

b
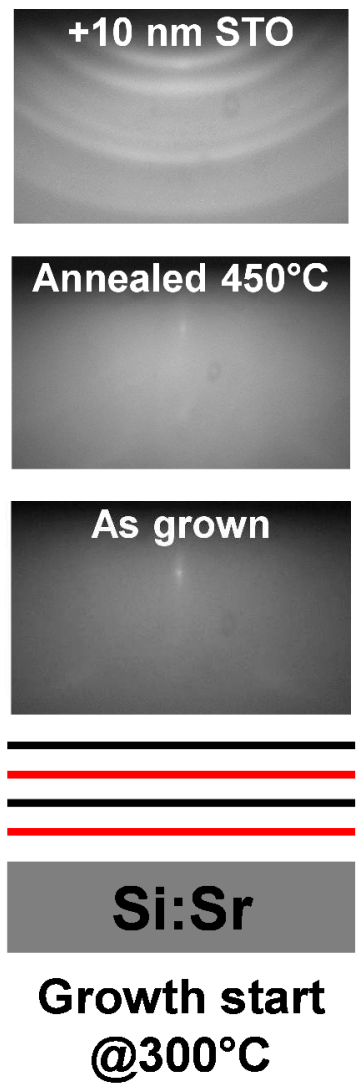

Figure 7: Effect on the growth start sequence on STO crystallization. a growth is initiated by an unstable $\mathrm{TiO}_{2} / \mathrm{SrO} / \mathrm{SrO} / \mathrm{TiO}_{2}$ sequence, spontaneously swapping to a stable $\mathrm{SrO} / \mathrm{TiO}_{2} / \mathrm{SrO} / \mathrm{TiO}_{2}$ sequence during annealing. RHEED shows that this deposit is initially amorphous. It also indicates clear STO crystallization after annealing, suggesting effectiveness of the $\mathrm{TiO}_{2} / \mathrm{SrO}$ swapping mechanism and showing that it allows STO crystal formation at $450^{\circ} \mathrm{C}$. Further growth of a $10 \mathrm{~nm}$ thick STO layer leads to good crystal quality. b No crystallization is observed during annealing after initial deposition of a $\mathrm{TiO}_{2} / \mathrm{SrO} / \mathrm{TiO}_{2} / \mathrm{SrO}$ sequence.

This growth sequence was designed to promote a vertical crystallization front instead of a lateral one. STO growth was initiated at low temperature $\left(300^{\circ} \mathrm{C}\right)$ on a $\mathrm{Sr}-$ treated $\mathrm{Si}$ surface by alternated deposition of $\mathrm{SrO}$ and $\mathrm{TiO}_{2}$ planes, with the sequence $\mathrm{TiO}_{2} / \mathrm{SrO} / \mathrm{SrO} / \mathrm{TiO}_{2}$. This stack is equivalent to $2 \mathrm{ML}$ of STO (globally no Sr-excess). The initially amorphous deposit was then annealed at $450^{\circ} \mathrm{C}$ under UHV. This sequence differs from the commonly used Motorola procedure detailed in Ref. 28 : in the Motorola procedure, $\mathrm{Sr}$ and $\mathrm{Ti}$ are co-deposited on the Sr-treated surface while here the growth is initiated by an alternated deposition of $\mathrm{SrO}$ and $\mathrm{TiO}_{2}$ monolayers. In particular, the deposition of a $\mathrm{TiO}_{2}$ monolayer on top of a double $\mathrm{SrO}$ layer is aimed at promoting STO crystallization by swapping of the top $\mathrm{SrO} / \mathrm{TiO}_{2}$ layers. As a matter of fact, a streaky RHEED pattern (displayed in Fig. 7a) was observed after annealing at $450^{\circ} \mathrm{C}$ attesting for actual formation of a well ordered STO crystal. Further 
STO growth was then continued at $45^{\circ} \mathrm{C}$ by $\mathrm{Sr}$ and Ti codeposition under $\mathrm{O}_{2}$, leading to the well contrasted RHEED pattern displayed in Fig. 7a attesting for good STO structural quality. For comparison, the same procedure was applied by starting the growth with an alternated $\mathrm{TiO}_{2} / \mathrm{SrO} / \mathrm{TiO}_{2} / \mathrm{SrO}$ stack (Fig. $7 \mathrm{~b}$ ). In this case, no crystallization was observed during the UHV annealing step, and further STO growth at higher temperature resulted in the formation of a STO polycrystal. This experiment shows that STO crystallization can be enhanced by engineering the starting growth sequence at the halfmonolayer scale to promote implementation of the knitting machine mechanism. It is worth noting that such engineering is effective even if the starting growth stack is amorphous, showing that local order is the key element for the onset of STO crystallization. Interestingly, this experiment also shows that globally stoichiometric STO, with no Sr-excess, can crystallize on $\mathrm{Si}$ at moderate temperature, and that the $\mathrm{Sr}$ excess required to crystallize thicker films formed by $\mathrm{Sr}$ and $\mathrm{Ti}$ co-deposition is only needed to provide $\mathrm{SrO}$ termination to each growing crystallite. This excess is damaging because it implements a lateral knitting machine mechanism.

Oppositely, using the growth sequence proposed here should allow avoiding $\mathrm{SrO}$ stacking fault formation and the related antiphase domain microstructure detrimental for the structural quality of the thin layer. As a matter of fact, it does not involve any excess $\mathrm{Sr}$ so that there is no material available for antiphase boundary formation. Moreover, it is expected to promote the onset of a "vertical" knitting machine mechanism since the deposited stack is a truly two-dimensional crystal seed, expected to promote vertical propagation of the growth front instead of the nucleation of crystallites, at the root of lateral growth and therefore of antiphase boundary formation. Further studies and optimizations are however required to demonstrate the efficiency of such growth strategy in avoiding the formation of antiphase domains. Lastly, it is worth noting that the knitting machine mechanism described here is not specific of the STO/Si system, and can obviously be employed to obtain crystallization of other perovskite oxides at moderate temperature. Therefore, it offers very promising prospects for the integration of crystalline perovskite oxides on semiconductors or other substrates by circumventing the issue of parasitic interface reactions.

\section{ASSOCIATED CONTENT}

Supporting Information

This material is available free of charge via the Internet at http://pubs.acs.org.

\section{AUTHOR INFORMATION}

Corresponding Author: *Guillaume Saint-Girons

e-mail: guillaume.saint-girons@ec-lyon.fr

\section{Author Contributions}

The manuscript was written through contributions of all authors. All authors have given approval to the final version of the manuscript.

\section{Funding Sources}

This work was partly supported by the European projects SITOGA (STREP FP 7 , grant number 619456) and TIPS (ICT $\mathrm{H} 2020$, grant number 107347) as well as by the French ANR programs HIRIS and DIAMWAFEL.

\section{ACKNOWLEDGMENT}

The HAADF-STEM microscopy work was conducted at the Center for Nanophase Materials Sciences, which is a DOE Office of Science User Facility. J.G. also acknowledges the Ramon y Cajal program (RYC-2012-11709). 


\section{REFERENCES}

${ }^{1}$ Ramanathan, S. (editor) Thin Film Metal Oxides: Fundamentals and Applications in Electronics and Energy; Springer: US, 2010.

${ }^{2}$ Kolpak, A. M. and Ismail-Beigi, S. Thermodynamic stability and growth kinetics of epitaxial $\mathrm{SrTiO}_{3}$ on silicon. Phys. Rev. B 2011, 83, 165318.

${ }^{3}$ Moon, B and Ishiwara, H. Roles of buffer layers in epitaxial growth of $\mathrm{SrTiO}_{3}$ films on silicon substrates. Jap. Journal of Appl. Phys. 1994, 33, 1472-1477.

4 Tambo, T.; Nakamura, T.; Maeda, K.; Ueba, H. and Tatsuyama, C. Molecular beam epitaxy of $\mathrm{SrTiO}_{3}$ films on Si (100)-2× 1 with $\mathrm{SrO}$ buffer layer. Jap. Journal of Appl. Phys. 1998, 37, 44544459 .

McKee, R. A.; Walker, F. J. and Chisholm, M. F. Crystalline oxides on silicon: the first five monolayers. Phys. Rev. Lett. 1998, 81, 3014-3017.

${ }^{6}$ Wei, Y.; Hu, X.; Liang, Y.; Jordan, D.C.; Craigo, B.; Droopad, R.; Yu, Z.; Demkov, A. A.; Edwards, J. L. and Ooms W. J. Mechanism of cleaning $\mathrm{Si}(100)$ surface using $\mathrm{Sr}$ or $\mathrm{SrO}$ for the growth of crystalline $\mathrm{SrTiO}_{3}$ films. J. Vac. Sci. Technol. B 2oo2, 20, 14021405 .

${ }^{7}$ Norga, G .J.; Guiller, A.; Marchiori, C.; Locquet, J. P.; Siegwart, H.; Halley, D.; Rossel, C.; Caimi, D.; Seo, J. W. and Fompeyrine, J. Growth of Perovskites with Crystalline Interfaces on Si(100). Mat. Res. Soc. Symp. Proc. 2004, 786, E7.3.1-E7.3.8.

${ }^{8}$ Delhaye, G. ; Merckling, C.; El-Kazzi, M.; Saint-Girons, G.; Gendry, M.; Robach, Y.; Hollinger, G.; Largeau, L. and Patriarche, G. Structural properties of epitaxial $\mathrm{SrTiO}_{3}$ thin films grown by molecular beam epitaxy on Si(oo1).J. Appl. Phys. 2006, 100, 124109 .

${ }^{9}$ He, J. Q.; Jia, C. L., Vaithyanathan, V.; Schlom, D. G.; Schubert, J.; Gerber, A.; Kohlstedt, H. H. and Wang, R. H. Interfacial reaction in the growth of epitaxial $\mathrm{SrTiO}_{3}$ thin films on (oo1) Si substrates. J. Appl. Phys. 2005, 97, 104921.

${ }^{10}$ Norga, G. J.; Marchiori, C.; Rossel, C.; Guiller, A.; Locquet, J. P.; Siegwart, H.; Caimi, D.; Fompeyrine, J.; Seo, J.W. and Dieker C. Solid phase epitaxy of $\mathrm{SrTiO}_{3}$ on (Ba,Sr)O/Si(10o): The relationship between oxygen stoichiometry and interface stability. $J$. Appl. Phys. 2006, 99, o84102.

${ }^{11}$ Goncharova, L.; Starodub, D. G.; Garfunkel, E.; Gustafsson, T.; Vaithyanathan, V.; Lettieri, J. and Schlom, D. G. Interface structure and thermal stability of epitaxial $\mathrm{SrTiO}_{3}$ thin films on Si (oo1). J. Appl. Phys. 2006, 100, 014912.

${ }^{12}$ Mi, S. B.; Jia, C. L.; Vaithyanathan, V.; Houben, L.; Schubert, J.; Schlom, D. G. and Urban, K. Atomic structure of the interface between $\mathrm{SrTiO}_{3}$ thin films and Si (oo1) substrates. Appl. Phys. Lett. 2008, 93, 101913.

13 Park, J.; Baek, S.; Bark, C.; Biegalski, M. and Eom, C. Quasisingle-crystal (oo1) $\mathrm{SrTiO}_{3}$ templates on Si.Appl. Phys. Lett. 2009, 95, 061902.

${ }^{14}$ Biegalski, M. D.; Fong, D. D.; Eastman, J. A.; Fuoss, P. H.; Streiffer, S. K.; Heeg, T.; Schubert, J.; Tian, W.; Nelson, C. T.; Pan, X. Q.; Hawley, M. E.; Bernhagen, M.; Reiche, P.; Uecker, R.; Trolier-McKrinsty, S. and Schlom, D. G. Critical thickness of high structural quality $\mathrm{SrTiO}_{3}$ films grown on orthorhombic (101) $\mathrm{DyScO}_{3}$. J. Appl. Phys. 2oo8, 104, 114109.

15 Delhaye, G.; El-Kazzi, M.; Gendry, M.; Hollinger, G. and Robach, Y. Hetero-epitaxy of $\mathrm{SrTiO}_{3}$ on $\mathrm{Si}$ and control of the interface. Thin Solid Films 2007, 515, 6332-6336.

${ }^{16}$ Niu, G.; Saint-Girons, G.; Vilquin, B.; Delhaye, G.; Maurice, J. L.; Botella, C.; Robach, Y. and Hollinger, G. Molecular beam epitaxy of $\mathrm{SrTiO}_{3}$ on $\mathrm{Si}$ (oo1): Early stages of the growth and strain relaxation. Appl. Phys. Lett. 2009, 95, 062902.

${ }^{17}$ Niu, G.; Vilquin, B.; Penuelas, J.; Botella, C.; Hollinger, G. and Saint-Girons, G. Heteroepitaxy of $\mathrm{SrTiO}_{3}$ thin films on $\mathrm{Si}$ (oo1) using different growth strategies: Toward substratelike quality. J. Vac. Sci. Technol. B 2011, 29, 041207.

18 Lettieri, J. Critical Issues of Complex, Epitaxial Oxide Growth and Integration with Silicon by Molecular Beam Epitaxy; PhD thesis: Pennsylvania state university, 2002.

${ }^{19}$ Lee, J. H.; Luo, G.; Tung, I. C.; Chag, S. H.; Luo, Z.; Malshe, M.; Gadre, M.; Bhattacharya, A.; Nakhmanson, S. N.; Eastman, J. A.; Hong, H.; Jellinek, J.; Morgan, D.; Fong, D. D. and Freeland, J. W. Dynamic layer rearrangement during growth of layered oxide films by molecular beam epitaxy. Nature Mater. 2014, 13, 879883.

${ }^{20}$ Murata, M.; Wakino, K. and Ikeda, S. X-ray photoelectron spectroscopic study of perovskite titanates and related compounds: an example of the effect of polarization on chemical shifts. J. Electron. Spec. Rel. Phen. 1975, 6, 459-464.

${ }^{21}$ Treske, U. Observation of strontium segregation in LaA$1 \mathrm{O}_{3} / \mathrm{SrTiO}_{3}$ and $\mathrm{NdGaO}_{3} / \mathrm{SrTiO}_{3}$ oxide heterostructures by X-ray photoemission spectroscopy. Appl. Phys. Lett. Mater. 2014, 2, 012108 .

${ }^{22}$ Vasquez, R. P. X-ray photoelectron spectroscopy study of Sr and Ba compounds. J. Electron. Spec. Rel. Phen. 1991, 56, 217-240.

${ }^{23}$ Kobayashi, D. Sr surface segregation and water cleaning for atomically controlled $\mathrm{SrTiO}_{3}(\mathrm{Oo1})$ substrates studied by photoemission spectroscopy. J. Electron. Spec. Rel. Phen. 2005, 144, 443446.

${ }^{24}$ Ohnishi, T.; Shibuya, K.; and Yamamoto, T. Defects and transport in complex oxide thin films. J. Appl. Phys 2008, 103, 103703.

${ }^{25}$ Brooks, C.; Kourkoutis, L. F.; Heeg, T.; Schubert, J.; Muller, D. A. and Schlom, D. G. Growth of homoepitaxial $\mathrm{SrTiO}_{3}$ thin films by molecular-beam epitaxy. Appl. Phys. Lett. 2009, 94,162905 .

${ }^{26}$ Niu, G.; Penuelas J.; Largeau, L.; Vilquin, B. ; Maurice, J. L. ; Botella, C.; Hollinger G. and Saint-Girons, G. Evidence for the formation of two phases during the growth of $\mathrm{SrTiO}_{3}$ on silicon. Phys. Rev. B 2011, 83, 054105.

${ }^{27}$ Wu, H. W.; Aoki, T.; Posadas, A. B. and Demkov, A. A. Antiphase boundaries at the $\mathrm{SrTiO}_{3} / \mathrm{Si}(\mathrm{ool})$ interface studied using aberration-corrected scanning transmission electron microscopy. Appl. Phys. Lett. 2016, 108, 091605.

${ }^{28}$ Li, H.; Hu, X.; Wei, Y.; Yu, Z.; Zhang, X.; Droopad, R.; Demkov, A. A.; Edwards Jr., J.; Moore, K.; Ooms, W.; Kumik, J. and Fejes, P. Two dimensional growth of high-quality strontium titanate thin films on Si. J. Appl. Phys. 2003, 93, 4521-4525.

${ }^{29}$ Lettieri, J.; Haeni, J. H. and Schlom, D. G. Critical issues in the heteroepitaxial growth of alkaline-earth oxides on silicon. J. Vac. Sci. Technol. A 2002, 20, 1332-1340.

${ }^{30}$ Carretero-Genevrier, A.; Gich, M.; Picas, L.; Gazquez, J.; Drisko, G. L.; Boissière, C.; Grosso, D.; Rodriguez-Carvajal, J. and Sanchez, C. Soft-chemistry-based routes to epitaxial $\alpha$-quartz thin films with tunable textures. Science 2013, 340, 827-831.

${ }^{31}$ Jacob, K. T. and Rajitha, G. Thermodynamic properties of strontium titanates: $\mathrm{Sr}_{2} \mathrm{TiO}_{4}, \mathrm{Sr}_{3} \mathrm{Ti}_{2} \mathrm{O}_{7}, \mathrm{Sr}_{4} \mathrm{Ti}_{3} \mathrm{O}_{10}$, and $\mathrm{SrTiO}_{3}$. J. Chem. Thermodynamics 2011, 43, 51-57. 
${ }^{32}$ Levin, E. M.; Robbins C. R. and McMurdie, H. F. Phase Diagrams for Ceramists; The American Ceramic Society: Columbus, 1964.

GRAPHICAL ABSTRACT

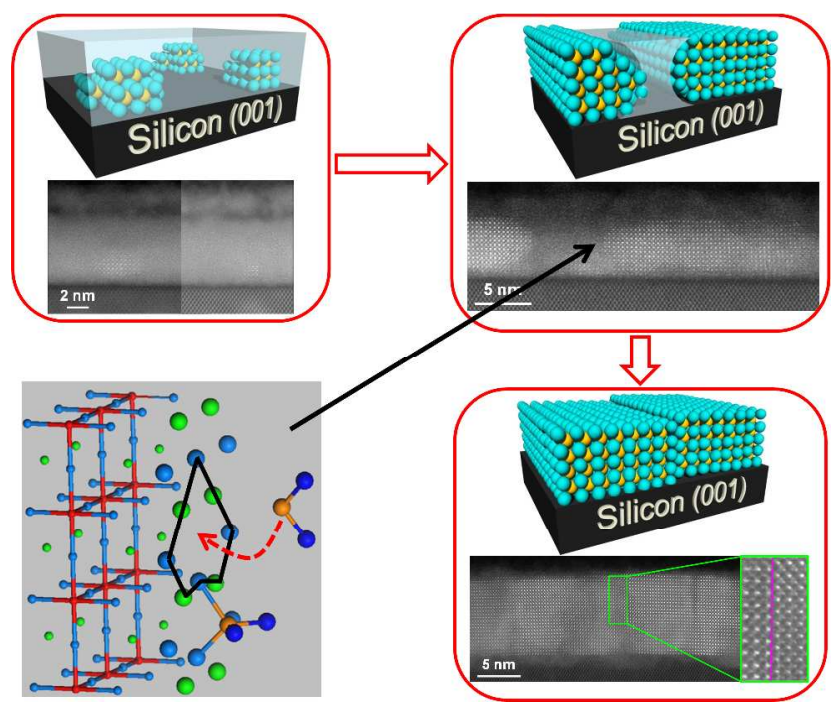

